Article

\title{
Kinetic and Surface Study of Single-Walled Aluminosilicate Nanotubes and Their Precursors
}

\author{
Nicolás Arancibia-Miranda ${ }^{1,2, *}$, Mauricio Escudey ${ }^{1,2}$, Mauricio Molina ${ }^{3}$ and \\ María Teresa García-González ${ }^{4}$
}

1 Center for the Development of Nanoscience and Nanotechnology (CEDENNA), Santiago 9170124 , Chile; E-Mail: mauricio.escudey@usach.cl

2 Faculty of Chemistry and Biology, University of Santiago of Chile, Av. B. O’Higgins, Santiago 3363, Chile

3 Departament of Industry, Federico Santa María Technical University, Av. Santa María 6400, Santiago 766-0251, Chile; E-Mail: mauricio.molina@usm.cl

4 Institute for Agricultural Sciences, Spanish National Research Council, Serrano 115-dup., Madrid 28006, Spain; E-Mail: mtgg@ccma.csic.es

* Author to whom correspondence should be addressed; E-Mail: nicolas.arancibia@usach.cl; Tel.: +56-22-718-1048.

Received: 19 December 2012; in revised form: 10 February 2013 / Accepted: 11 February 2013 / Published: 1 March 2013

\begin{abstract}
The structural and surface changes undergone by the different precursors that are produced during the synthesis of imogolite are reported. The surface changes that occur during the synthesis of imogolite were determined by electrophoretic migration (EM) measurements, which enabled the identification of the time at which the critical precursor of the nanoparticles was generated. A critical parameter for understanding the evolution of these precursors is the isoelectric point (IEP), of which variation revealed that the precursors modify the number of active $\equiv \mathrm{Al}-\mathrm{OH}$ and $\equiv \mathrm{Si}-\mathrm{OH}$ sites during the formation of imogolite. We also found that the IEP is displaced to a higher $\mathrm{pH}$ level as a consequence of the surface differentiation that occurs during the synthesis. At the same time, we established that the $\mathrm{pH}$ of the reaction $\left(\mathrm{pH}_{\mathrm{rx}}\right)$ decreases with the evolution and condensation of the precursors during aging. Integration of all of the obtained results related to the structural and surface properties allows an overall understanding of the different processes that occur and the products that are formed during the synthesis of imogolite.
\end{abstract}


Keywords: metal oxide nanotubes; imogolite; growth kinetics; isoelectric point; electrophoretic characterisation

\section{Introduction}

Two low-range-ordered aluminosilicates can be found in volcanic ash-derived soils, one of which consists of single-walled aluminosilicate nanotubes or metal-oxide nanotubes, and is known as imogolite [1]. Its stoichiometry is $(\mathrm{OH})_{3} \mathrm{Al}_{2} \mathrm{O}_{3} \mathrm{SiOH}$, and it is characterized by a hollow cylindrical structure with an average outer diameter of $2.5 \mathrm{~nm}$ and with a length that varies from $100 \mathrm{~nm}$ to several micrometres [2,3]. The simplicity of its synthesis and its high chemical flexibility [4,5], which results from the surface groups that constitute and functionalize the imogolite in a natural way (silanols, $\equiv \mathrm{Si}-\mathrm{OH}$, on the inner surface and aluminols, $\equiv \mathrm{Al}-\mathrm{OH}$, on the outer surface), have rendered this material an excellent substrate for various nanotechnological applications [6-8].

The low yield is the main limitation of the different synthetic methods $[5,9,10]$. The research conducted to elucidate the mechanism of formation of imogolite has revealed that the subnanometric precursors are formed in the coprecipitation stage and are the key to inducing a self-assembly process during aging [11-14]. Studies on the mechanism of formation of imogolite, proposed in the literature, agree that the curved structure is due to a series of substitutions of the surface $-\mathrm{OH}$ groups of the $\equiv$ Al-OH groups of the gibbsite layer with tetrahedral $\mathrm{O}_{3} \mathrm{SiOH}$. The substitutions result in a curved structure because of the different lengths of the Al-O and Si-O bonds $(0.19 \mathrm{~nm}$ and $0.16 \mathrm{~nm}$, respectively) [1,2]. A direct consequence of these substitutions is the differentiation of the surface active sites in the precursors, one of which is enriched in $\equiv \mathrm{Al}-\mathrm{OH}$ groups and the other in $\equiv \mathrm{Si}-\mathrm{OH}$ groups.

The synthesis of imogolite in natural systems, or under controlled laboratory conditions, is affected by two key factors: the concentration of the reagents in solution at the beginning of the synthesis (which must have an $\mathrm{Al} / \mathrm{Si}$ ratio of two, and must be present in concentrations on the order of $\mathrm{mM})[15,16]$ and the temperature (which determines the formation kinetics of the nanoparticles) [17]. These factors play an important role in the growth, dissolution, aggregation, and aging of imogolite.

The formation and characterisation of imogolite has been studied by techniques such as FTIR spectroscopy, X-ray diffraction (XRD), transmission electron microscopy (TEM), X-ray absorption spectroscopy (XAS), nuclear magnetic resonance (NMR), electrospray ionisation mass spectrometry (ESI-MS), and small-angle X-ray scattering (SAXS) $[11,18,19]$. However, the experimental conditions of the synthesis and the particular limitations of each characterization technique have hindered the determination of an adequate growth mechanism for this aluminosilicate. Research on structures analogous to imogolite, such as aluminogermanates $\left((\mathrm{OH})_{3} \mathrm{Al}_{2} \mathrm{O}_{3} \mathrm{GeOH}\right)$, have led to significant progress toward a general mechanism that explains the formation of imogolite [18-20].

Independent of the specific mechanism through which imogolite is obtained [18,19], the magnitude of the structural changes and the marked differences in the chemical reactivity of the groups that are formed during the aging process $\left(\equiv \mathrm{Al}_{2}-\mathrm{OH}, \equiv \mathrm{Al}-\mathrm{OH}\right.$ and $\left.\equiv \mathrm{Si}-\mathrm{OH}\right)$ allow the use of surface characterisation techniques, such as electrophoretic migration (EM). The high sensitivity of the EM 
technique to small surface changes [20-22] allows the evolution of the precursors and their later assembly and growth to be followed.

Electrophoretic migration is a surface characterisation technique that has been widely used to study the surface of catalysts, ore flotation, and pedology, because it allows a good description of the phenomena that occur on a surface [23-27]. The isoelectric point (IEP) of a sample can be determined through EM measurements. This parameter corresponds to the $\mathrm{pH}$ at which the net charge of the diffuse layer $(\sigma D)$ is equal to zero and can be used as a descriptive parameter of the surface changes that affect a particle, such as surface enrichment, coating, and hydration [21,22,27]. Although the $\equiv \mathrm{Al}-\mathrm{OH} / \equiv \mathrm{Si}-\mathrm{OH}$ active sites ratio is important in an aluminosilicate, its surface distribution is even more significant for defining its IEP.

Several authors have reported that the point of zero charge (PZC) varies with the size of a nanoparticle as a consequence of the changes in composition that occur during growth [28,29]. Within this framework, the objective of this research is to evaluate the structural changes that occur during the aging process of imogolite synthesis-from the monomeric precursors to the formation of the nanotubes - based on the changes in the surface $\equiv \mathrm{Al}-\mathrm{OH} / \equiv \mathrm{Si}-\mathrm{OH}$ ratio, as reflected in the evolution of the IEP of each precursor and in the changes in the reaction $\mathrm{pH}$ that occur during the synthesis, along with other techniques.

\section{Experimental Section}

Reagent-grade solvents were used. The imogolite sample was prepared using tetraethyl orthosilicate (99.995\%, Sigma-Aldrich, St. Louis, MO, USA), NaOH (99.996\%, Merck, Darmstadt, Germany), $\mathrm{AlCl}_{3}$ (99.998\%, Merck), $\mathrm{HCl}$ (99.998\%, Merck), $\mathrm{CH}_{3} \mathrm{COOH}$ (99.998\%, Merck) and $\mathrm{NH}_{4} \mathrm{OH}$ (99.997\%, Merck).

Synthesis of Imogolite. Tetraethyl orthosilicate (TEOS) was added dropwise to a stirred $5 \mathrm{mM}$ solution of $\mathrm{AlCl}_{3}$ solution until the $\mathrm{Al}$ :Si ratio was 1.8, and the mixture was allowed to stand for 45 min under vigorous stirring. A NaOH $\left(10^{-1} \mathrm{M}\right)$ solution was subsequently added at a rate of $0.3 \mathrm{~mL} / \mathrm{min}$ until the $\mathrm{pH}$ of the solution was 5.0. The $\mathrm{pH}$ was immediately decreased to 4.5 by the dropwise addition of $\mathrm{HCl}\left(10^{-1} \mathrm{M}\right)$ and $\mathrm{CH}_{3} \mathrm{COOH}\left(2 \times 10^{-1} \mathrm{M}\right)$ solutions. The resulting clear solution was stirred for $3 \mathrm{~h}$ and then reacted at $95{ }^{\circ} \mathrm{C}$ under reflux. The remaining sample was transferred to a vessel under vigorous stirring. A $0.1 \mathrm{M}$ ammonia solution was carefully added until the $\mathrm{pH}$ was 8.0. The solids were concentrated and washed with deionized water by centrifugation at $9000 \mathrm{rpm}$ for $30 \mathrm{~min}$ until the specific conductivity was reduced to less than $0.78 \mathrm{dS} / \mathrm{m}$ [13].

Electrophoretic Measurements and Isoelectric Point (IEP). The samples were suspended in $200 \mathrm{~mL}$ of $\mathrm{KCl}\left(1 \times 10^{-3} \mathrm{M}\right)$. The $\mathrm{pH}$ was adjusted with $\mathrm{HCl}$ or $\mathrm{KOH}\left(1 \times 10^{-2} \mathrm{M}\right)$, and electrophoretic mobility measurements were performed on a Zetameter apparatus. The IEP was obtained from the plot of electrophoretic mobility vs. $\mathrm{pH}$.

Point of Zero Salt Effect (PZSE). The surface charge characteristics of the aluminosilicate samples were measured by potentiometric titration. Aluminosilicate suspensions were prepared by mixing $300 \mathrm{mg}$ of solid samples with $100 \mathrm{~mL}$ of $\mathrm{KCl}$ at different ionic strengths $\left(10^{-1}, 10^{-2}\right.$ and $\left.10^{-3} \mathrm{M}\right)$. The titrations were performed under an $\mathrm{N}_{2}$ atmosphere at a constant temperature of $25{ }^{\circ} \mathrm{C}$. The titrations 
were initiated at the original $\mathrm{pH}$, and $0.2 \mathrm{~mL}$ of $\mathrm{KOH}$ or $\mathrm{HCl}\left(10^{-1} \mathrm{M}\right)$ was added every $20 \mathrm{~min}$. The $\mathrm{pH}$ response of the electrode was calibrated with buffer solutions at $\mathrm{pH} 4.00,7.00$ and 10.00. The PZSE was determined by locating the common intersection point of the potentiometric titration curves at different ionic strengths.

Transmission Electron Microscopy (TEM). The samples were observed under a Zeiss EM 910 transmission electron microscope (Zeiss, Oberkochen, Germany) using an acceleration potential $80 \mathrm{kV}$. The samples were mounted onto carbon substrates prepared as follows: a drop of the sample, suspended in water, was transferred to the face of a freshly cleaved sheet of mica, and the solvent was allowed to evaporate. A thin layer of carbon was deposited onto the surface by vacuum evaporation. The carbon/product film was separated from the mica sheet by flotation on distilled water and was subsequently transferred to a perforated $\mathrm{Cu}$ support grid. Each sample was examined on a LEO 910 transmission electron microscope (Zeiss, Oberkochen, Germany) operated at $120 \mathrm{kV}$.

$X$-Ray Diffraction (XRD). XRD analyses were performed using oriented aggregates prepared by drying water suspensions of the samples on glass slides. Samples were scanned from $3^{\circ}$ to $70^{\circ} 2 \theta$ using a step size of $0.02^{\circ} 2 \theta$ and scanning for $1.0 \mathrm{~s}$ at each step. The X-ray patterns were collected using $\mathrm{CuK} \alpha$ radiation from a Philips $\mathrm{X}^{\prime}$ Pert diffractometer generator (Philips, Amsterdam, the Netherlands) and a theta/theta goniometer equipped with a $1.5^{\circ}$ divergence slit a $0.2^{\circ}$ receiving slit, a graphite diffracted-beam monochromator, and a scintillation counter.

Fourier-Transform Infrared Spectroscopy (FTIR). FTIR spectra of both aluminosilicate compounds were obtained on a Bruker Tensor 27 spectrometer (Bruker, Billerica, MA, USA). A 3-mg dry sample was compacted in a spectral-grade $\mathrm{KBr}$ matrix. The spectra were scanned 32 times at a resolution of $2 \mathrm{~cm}^{-1}$.

Specific Surface Area (SSA). The SSA and the micropore and mesopore volumes and diameters were determined from nitrogen adsorption-desorption isotherms measured on a Micromeritics model ASAP 2010 (Micromeritics, Norcross, GA, USA) and in a Carlo Erba Sorptmatic 900 (Carlo Erba, Milan, Italy) using the static volumetric method. Samples of $0.500 \mathrm{~g}$ were degassed at $483 \mathrm{~K}$ for $24 \mathrm{~h}$, with a residual vacuum of $0.532 \mathrm{~Pa}$. The SSA was calculated from the nitrogen adsorption isotherm at $77 \mathrm{~K}$ by the Brunauer-Emmett-Teller (BET) method (11). The micropore volume was calculated from the nitrogen adsorption at $77 \mathrm{~K}$ by the $t$-plot method; the volume and diameter of the mesopores were calculated from the adsorption/desorption nitrogen isotherm by the Barrett-Joyner-Halenda (BJH) method (11). All samples were analyzed in triplicate.

Data Analysis. A variance analysis was performed to compare the IEP and reaction $\mathrm{pH}\left(\mathrm{pH}_{\mathrm{rx}}\right)$ values at different aging times. The mean values were compared using the Tukey test $(p<0.01)$, which is a conservative test based on the distribution of statistic $q$ that allows multiple comparisons and corrects for the increasing risk of finding differences by chance (type I error). 


\section{Results and Discussion}

\subsection{Structural Characterisation}

The morphological changes of imogolite during the aging process were analyzed by FTIR spectroscopy, XRD, and TEM. The FTIR spectra collected at different preparation times showed the presence of three wide peaks at 1080,968 , and $590 \mathrm{~cm}^{-1}$, which correspond to the stretching of the $\mathrm{Si}-\mathrm{O}$ and $\mathrm{Si}-\mathrm{O}-\mathrm{Al}$ bonds and are consistent with the structure of proto-imogolite $(48 \mathrm{~h})$. After $72 \mathrm{~h}$ of aging, bands appeared at 990 and $939 \mathrm{~cm}^{-1}$, which belong to the Si-O stretching vibrations that are specific to tubular structures; these bands remained almost invariable throughout the aging time (Figure 1a) [5,30-32]. Changes in hydroxide bands were also observed in the $3500-3200 \mathrm{~cm}^{-1}$ range. After 72 of aging, $-\mathrm{OH}$ bands at 3300 and $3500 \mathrm{~cm}^{-1}$ associated with external $\equiv \mathrm{AlOH}$ and $\equiv \mathrm{Al}_{2} \mathrm{OH}$ were observed; in the same spectrum, a band at $3615 \mathrm{~cm}^{-1}$ associated with $\equiv \mathrm{Si}-\mathrm{OH}$ sites located in the inner surface of ring-type precursors was present (Figure 1a) [33].

Figure 1. Fourier-Transform Infrared Spectroscopy (FTIR) spectra (a) and X-Ray Diffraction (XRD) patterns (b) of the synthetic products at different aging times: (a) $0 \mathrm{~h}$, (b) $12 \mathrm{~h}$, (c) $24 \mathrm{~h}$, (d) $48 \mathrm{~h}$, (e) $72 \mathrm{~h}$, (f) $96 \mathrm{~h}$, and (g) $120 \mathrm{~h}$.
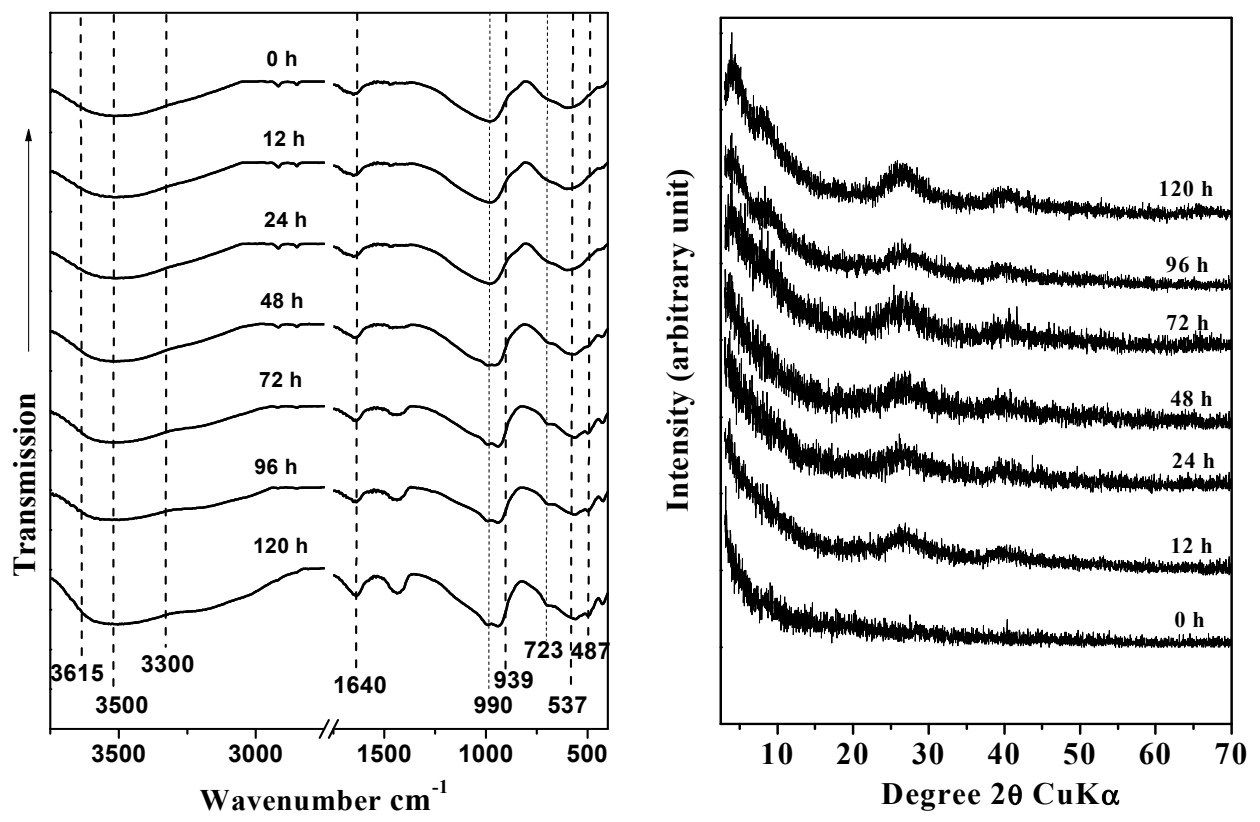

The evolution of the diffraction patterns of samples obtained at different aging times are summarized in Figure 1b. The XRD data show that the precursor formed after the coprecipitation process had ended corresponds to an amorphous aluminosilicate [34]. The precursor remained for the first $48 \mathrm{~h}$ of aging. We observed a better definition of the diffraction patterns of the precursors formed was observed as the aging progressed, as indicated by wide diffraction patterns at $72 \mathrm{~h}$ of aging, corresponding to $0.21,1.20,0.34$ and $0.22 \mathrm{~nm}$. These bands, which are characteristic of a paracrystalline structure, such as that of imogolite, remained almost invariable until the end of the aging process; the bands became more defined with time, which we interpreted as a sign of the extension of the aging process $[14,34,35]$. 
The TEM observations made during the first hours of the synthesis show that the precursors formed have an ill-defined and short-range structure under X-ray and that they reached a size of approximately $5 \mathrm{~nm}$ (Figure 2a).

As a consequence of aging and the increasing substitution of the $-\mathrm{OH}$ of the $\equiv \mathrm{Al}-\mathrm{OH}$ groups by $\mathrm{O}_{3} \mathrm{SiOH}$, the precursors start growing and forming complex oligomers with sizes smaller than $15 \mathrm{~nm}$ (Figure $2 \mathrm{~b}$ ). The TEM results indicate that the maximum structuring of the precursors was achieved between 48 and $72 \mathrm{~h}$ after the beginning of the aging process; the images show the condensation of nanotube pieces approximately 20 to $30 \mathrm{~nm}$ in size (Figure 2c), which evolve into the structure characteristic of imogolite (Figure 2d).

Based on nitrogen adsorption measurements, the textural properties of the products obtained at different aging times were determined (Table 1).

During the aging process, the BET surface area increases as a result of changes in the spatial arrangement and growth of the precursors (Figure 2) [36]. With the exception of SSA, after $72 \mathrm{~h}$ of aging, the textural properties of the precursors were similar to those of the end product (imogolite). These results are consistent with the XRD, FTIR and TEM data. During the aging process, under the experimental conditions considered, the SSA increased even after $120 \mathrm{~h}$, reaching $351 \mathrm{~m}^{2} \cdot \mathrm{g}^{-1}$ at $240 \mathrm{~h}$.

Figure 2. Transmission Electron Microscopy (TEM) images of products at different aging times: (a) $0 \mathrm{~h}$, (b) $24 \mathrm{~h},(\mathbf{c}) 72 \mathrm{~h}$, and (d) $120 \mathrm{~h}$.
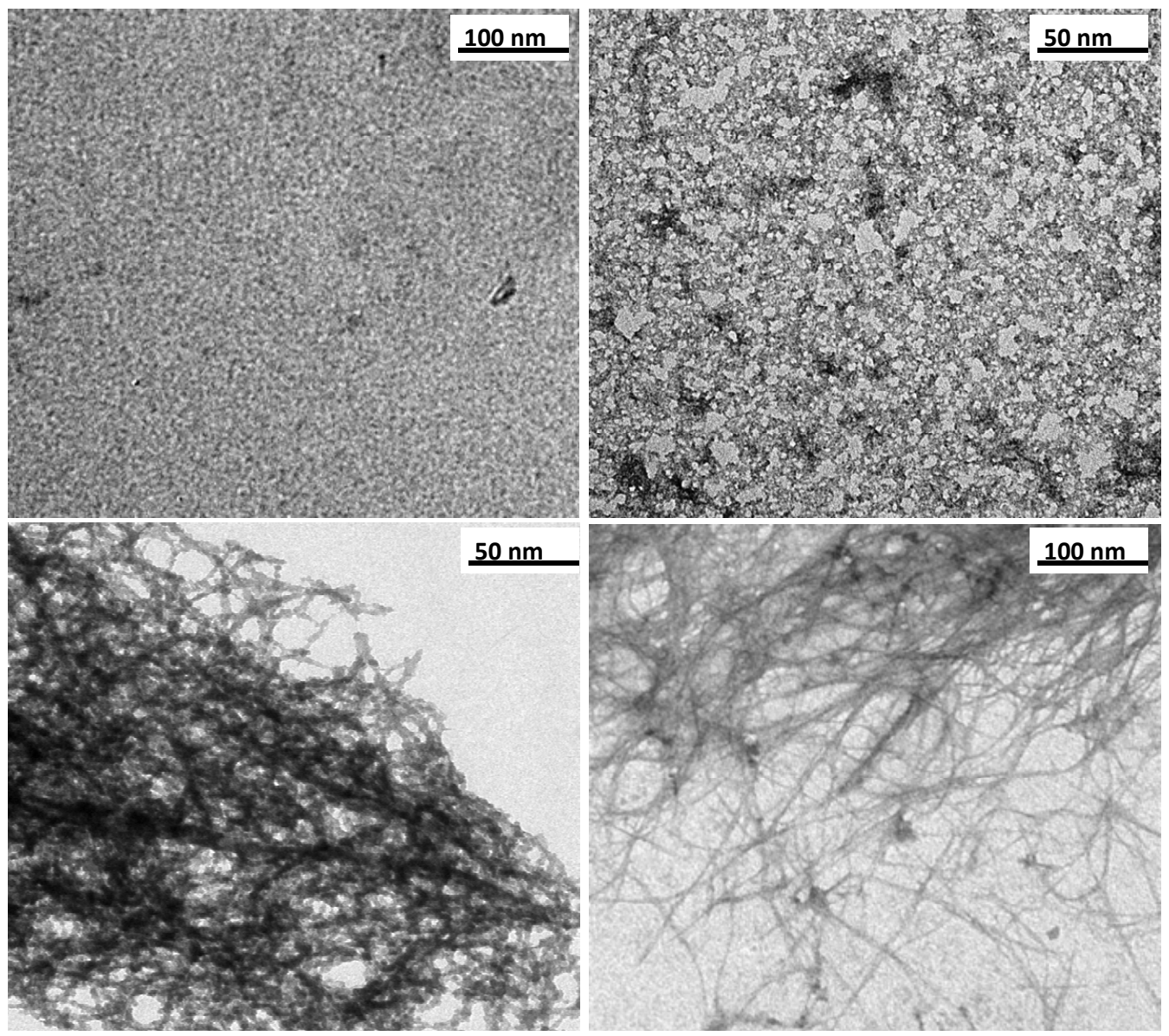
Table 1. Textural features of products obtained at different aging times.

\begin{tabular}{|c|c|c|c|c|c|}
\hline Time (h) & $\begin{array}{c}\begin{array}{c}\text { Surface area } \\
\left(\mathrm{m}^{2} / \mathrm{g}\right)\end{array} \\
\end{array}$ & $\begin{array}{c}\text { Pore volume }^{\mathrm{b}} \\
\left(\mathrm{cm}^{3} / \mathrm{g}\right)\end{array}$ & $\begin{array}{c}\text { Microporous } \\
\text { volume }^{\mathrm{c}}\left(\mathrm{cm}^{3} / \mathrm{g}\right)\end{array}$ & $\begin{array}{c}\text { Inner diameter } \\
(\mathrm{nm})\end{array}$ & $\begin{array}{c}\begin{array}{c}\text { Outer diameter } \\
(\mathrm{nm})\end{array} \\
\end{array}$ \\
\hline 0 & 170 & 0.10 & 0.04 & --- & --- \\
\hline 12 & 181 & 0.13 & 0.03 & --- & --- \\
\hline 24 & 197 & 0.15 & 0.03 & --- & --- \\
\hline 72 & 214 & 0.20 & 0.02 & 1.0 & 2.3 \\
\hline 96 & 253 & 0.23 & 0.02 & 1.0 & 2.5 \\
\hline 120 & 303 & 0.25 & 0.02 & 1.0 & 2.5 \\
\hline
\end{tabular}

Notes: ${ }^{a}$ Specific surface area, as calculated according to the BET (Brunauer-Emmett-Teller) method through multipoint calculation by choosing the result given by the best linear-fit in the 0.1 to $0.2 P / P^{0}$ range; the resulting estimated error is $3 \%$ of the obtained value. ${ }^{b}$ Pore volume was obtained from the $\mathrm{N}_{2}$ adsorption isotherm performed at $77 \mathrm{~K} .{ }^{\mathrm{c}}$ As derived by applying the $\alpha_{\mathrm{s}}$ method.

\subsection{Surface Characterization}

The IEP is a parameter that indicates the level of enrichment in $\equiv \mathrm{Si}-\mathrm{OH}$ and $\equiv \mathrm{Al}-\mathrm{OH}$ groups of the new surfaces that result from the aging process, and its value changes until it reaches the characteristic IEP of imogolite [24,36-38].

The variation of the IEP as a function of time is summarized in Table 2. The IEP obtained for the precursor formed after the coprecipitation of the starting products had ended suggests that the numbers of $\equiv \mathrm{Si}-\mathrm{OH}$, $\equiv \mathrm{Al}-\mathrm{OH}$ and $\equiv \mathrm{Al}_{2}-\mathrm{OH}$ groups are similar and that their distribution on the surface is heterogeneous (Table 2$)\left(t_{I} \rightarrow t_{I I}\right.$, Figure 3$)$.

Table 2. Isoelectric point (IEP), reaction $\mathrm{pH}\left(\mathrm{pH}_{\mathrm{rx}}\right), \Delta \mathrm{IEP} / \Delta \mathrm{t}$, and $\Delta \mathrm{pH}_{\mathrm{rx}} / \Delta \mathrm{t}$ as a function of the synthesis time.

\begin{tabular}{ccccc}
\hline Time (h) & $\mathbf{I E P}$ & $\Delta \mathbf{I E P} / \Delta \mathbf{t}$ & $\mathbf{p} \mathbf{H}_{\mathbf{r x}}$ & $\Delta \mathbf{p H}_{\mathbf{r x}} / \Delta \mathbf{t}$ \\
\hline 0 & $6.6 \mathrm{a}$ & 0 & $4.49 \mathrm{a}$ & 0 \\
12 & $7.1 \mathrm{~b}$ & 4.2 & $4.26 \mathrm{~b}$ & 1.90 \\
24 & $7.8 \mathrm{c}$ & 5.8 & $3.85 \mathrm{c}$ & 3.40 \\
48 & $8.5 \mathrm{~d}$ & 2.9 & $3.61 \mathrm{~d}$ & 1.80 \\
72 & $10.0 \mathrm{e}$ & 6.3 & $2.78 \mathrm{e}$ & 3.50 \\
96 & $10.3 \mathrm{ef}$ & 1.3 & $2.72 \mathrm{f}$ & 0.03 \\
120 & $10.6 \mathrm{fg}$ & 1.3 & $2.70 \mathrm{fg}$ & 0.01 \\
\hline
\end{tabular}

Note: Within columns, values followed by the same letter are not significantly different according to Tukey's test $(p<0.01)$. The $\Delta \mathrm{IEP} / \Delta \mathrm{t}$ and $\Delta \mathrm{pH}_{\mathrm{rx}} / \Delta \mathrm{t}$ values are amplified by a factor of 10 .

As the self-assembly of the precursors occurs, they evolve into more complex structures, and their IEPs shift to more basic $\mathrm{pH}$ values. This evolution is the result of the increased substitution of $-\mathrm{OH}$ groups from $\equiv \mathrm{Al}-\mathrm{OH}$ by $\mathrm{O}_{3} \mathrm{SiOH}$ during aging (self-assembly), which causes the $\equiv \mathrm{Al}-\mathrm{OH}, \equiv \mathrm{Al}_{2}-\mathrm{OH}$ and $\equiv \mathrm{Si}-\mathrm{OH}$ groups to become localized on separate surfaces and the $\equiv \mathrm{Al}-\mathrm{OH}, \equiv \mathrm{Al}_{2}-\mathrm{OH}$ groups to become exposed as outer active sites $\left(\mathrm{t}_{\mathrm{II}} \rightarrow \mathrm{t}_{\mathrm{III}} \rightarrow \mathrm{t}_{\mathrm{IV}}\right.$, Figure 3 ) [38-40].

Between 48 and $72 \mathrm{~h}$ of aging, the substitutions are most significant, which results in some of the formed precursors to be completely closed (i.e., to form ring structures). The surface characteristics of 
these types of precursors would account for the increase in the IEP by $1.5 \mathrm{pH}$ units because the outer surface has a clear predominance of $\equiv \mathrm{Al}-\mathrm{OH}$ and $\equiv \mathrm{Al}_{2}-\mathrm{OH}$ groups $\left(\mathrm{t}_{\mathrm{V}}\right.$, Figure 3$)[2,38,40]$.

Figure 3. Structural evolution of the precursors formed during the synthesis of imogolite.

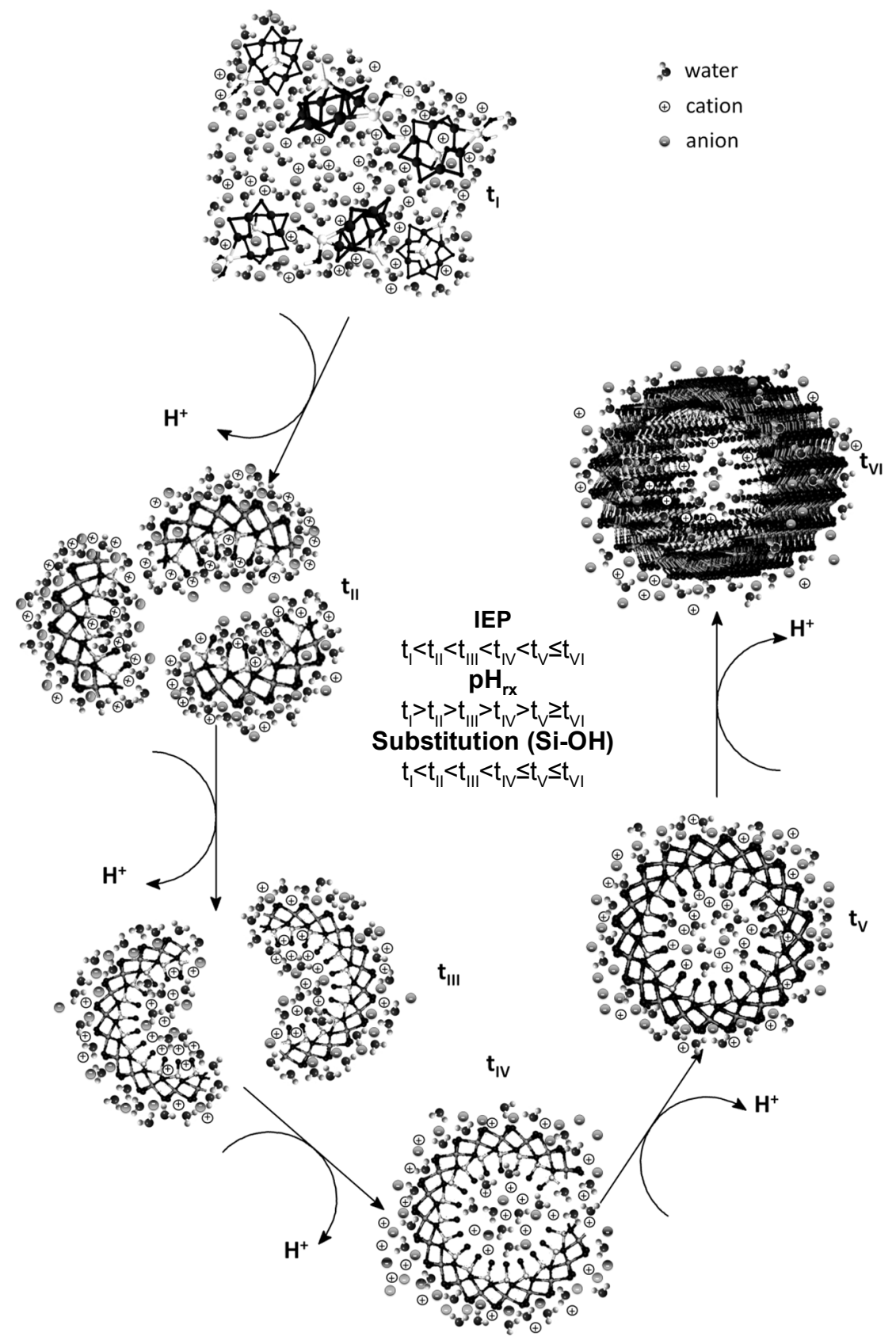

After the ring structure has formed, the IEP variation is minimal because the $\equiv \mathrm{Si}-\mathrm{OH}$ groups are found preferentially on the inner surface of the precursor, which decreases their contribution to the surface charge of the imogolite $\left(t_{v}\right.$, Figure 3$)$ observed by electrophoretic migration. Toward the end of the synthesis (96-120 h), the IEP values obtained are close to those reported for gibbsite (10.6-11.0), a main constituent of the outer surface of imogolite ( $\mathrm{t}_{\mathrm{VI}}$, Figure 3) [35-41]. The IEP increased after $120 \mathrm{~h}$ and reached 10.7, which, according to the Tukey test, was not a significant change. To understand the IEP values and variations observed in the precursors and in imogolite, it is important to consider that, in pure silicon and aluminium oxides, this parameter assumes values of approximately 
two and nine, respectively [39] and that, in binary compounds such as allophane (a short-range-ordered aluminosilicate), an IEP lower than that of imogolite has been determined, despite both having a similar Al/Si ratio [34]. This result is explained by the close relationship between the structural and surface arrangement of the $\equiv \mathrm{Si}-\mathrm{OH}$ and $\equiv \mathrm{Al}-\mathrm{OH}$ groups and the IEP value.

The contribution of $\equiv \mathrm{Si}-\mathrm{OH}$ groups to $\mathrm{EM}$ measurements decreases as the imogolite grows because the exposed surface contains mostly $\equiv \mathrm{Al}_{2}-\mathrm{OH}$ and $\equiv \mathrm{Al}-\mathrm{OH}$ sites, which prevents the determination of the contribution of the $\equiv \mathrm{Si}-\mathrm{OH}$ groups at the charge level. Through a comparison of the IEP (determined by electrokinetic measurements) and the PZSE (determined by potentiometric measurements), the issue of whether silanol groups participate in ion-exchange reactions after the formation of imogolite nanotubes can be determined (Figure 4). The IEP and PZSE pH values agree only when the active surface sites that participate in charge generation are the same [27].

Figure 4. Potentiometric titration curves of imogolite at three different $\mathrm{KCl}$ concentrations.

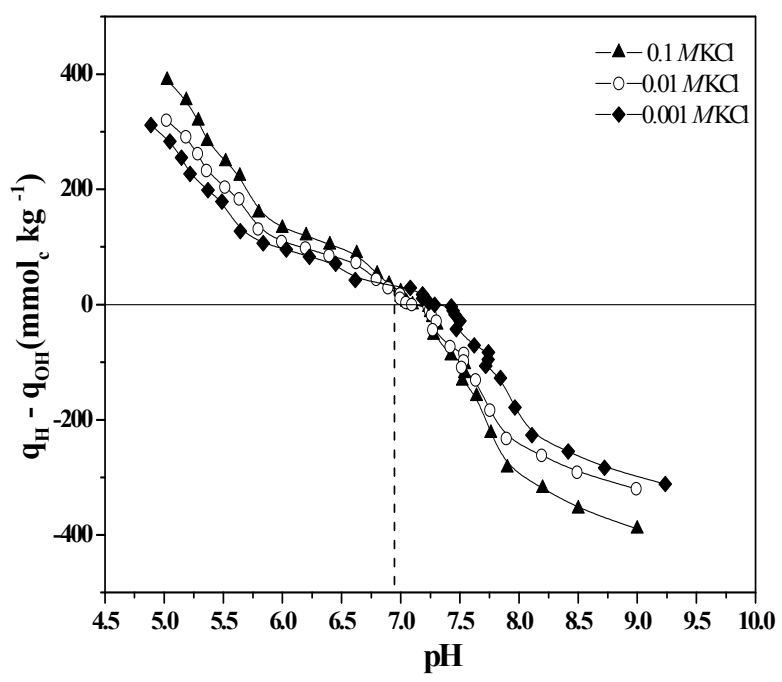

An IEP of 10.5 was determined for imogolite, which shows the influence of the $\equiv \mathrm{Al}_{2}-\mathrm{OH}$ and $\equiv \mathrm{Al}-\mathrm{OH}$ groups that dominate the outer surface composition of the nanotubes $[2,34,38-40]$. In contrast, the PZSE of 6.8 is the result of proton exchange reactions that occur on both internal $\equiv \mathrm{Si}-\mathrm{OH}$ and external $\equiv \mathrm{Al}-\mathrm{OH}$ active sites $[27,34]$.

The analyses of the IEP and PZSE indicate that the surface changes drastically and shows that the outer surface $\mathrm{Al} / \mathrm{Si}$ ratio increases under the effect of the aging process. This phenomenon conditions the arrangement of the imogolite reactive groups and explains the differences in the observed IEP and PZSE values; these differences are attributable to the presence of two different types of functional groups dominating the inner and outer surfaces of the tubular structure of the nanoparticle.

These results confirm that the active sites of the outer surface of imogolite are Al-OH enriched and that the $\equiv \mathrm{Si}-\mathrm{OH}$ groups located on the inner surface of the imogolite nanotube are also part of the reactive groups during the potentiometric titration (Figure 4) [4,27,40]. During aging, another synthesis parameter, the $\mathrm{pH}$ of reaction $\left(\mathrm{pH}_{\mathrm{rx}}\right)$, decreases due to condensation of the precursors, which occurs through an oxolation mechanism (Figure 5) - a process that releases $\mathrm{H}_{3} \mathrm{O}^{+}$into the solution $[12,16,30,38]$. 
Figure 5. Schematic representation of the substitutions of $-\mathrm{OH}$ groups of the $\mathrm{Al}$ precursors by the orthosilicate anion.
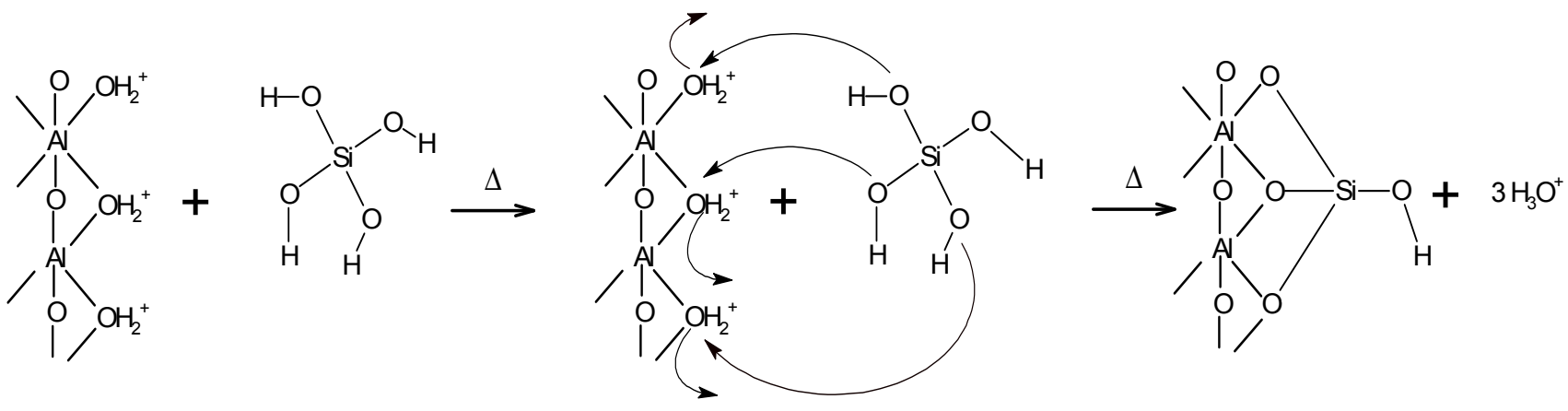

\section{Oxolation mechanism}

The variation of the $\mathrm{pH}$ of reaction is similar to that of the IEP during the aging process within the same time interval, which shows that both parameters are dependent on the structural changes to which the precursors are subjected during aging. A more significant way of observing the effect of structural changes on the $\mathrm{pH}_{\mathrm{rx}}$ is to represent the variation of this parameter as a function of aging time (Table 2 and Figure 6a).

Figure 6. Changes in the reaction $\mathrm{pH}\left(\Delta \mathrm{pH}_{\mathrm{rx}} / \Delta \mathrm{t}\right)$ and the isoelectric point $(\Delta \mathrm{IEP} / \Delta \mathrm{t})$ as functions of the aging time.
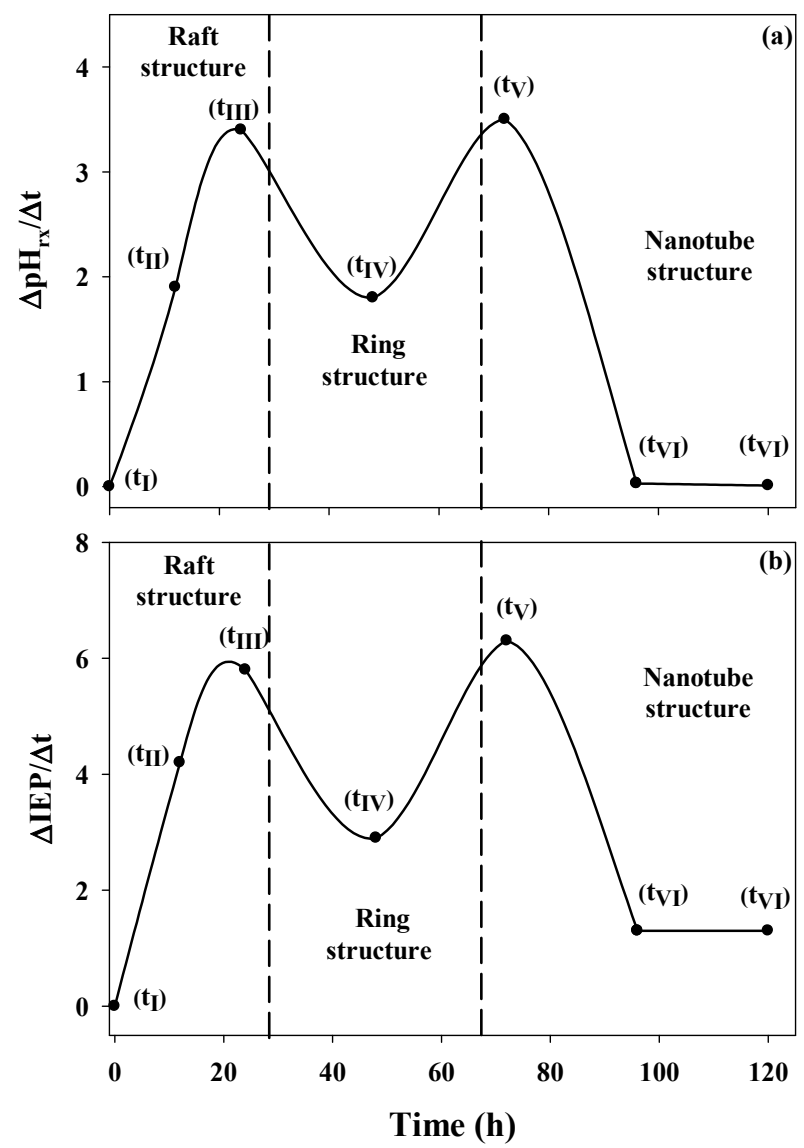
This graph clearly shows that the most significant structural changes result in the most important changes in $\mathrm{pH}_{\mathrm{rx}}$. Three important changes occur: the first is the change from the monomeric and oligomeric precursors ( $t_{I}$, Figure 3 ) to the raft-type structure $\left(t_{I I I}\right.$, Figure 3$)$; the second change corresponds to the path from the raft-type structures to rings $\left(t_{I I I} \rightarrow t_{V}\right.$, Figure 3$)$; and the third change accounts for the one-dimensional growth of the ring-type structure until it forms the imogolite nanotube $\left(t_{V} \rightarrow t_{V I}\right.$, Figure 3$)$. A similar association can be made when the change in the IEP as a function of the change in time $(\Delta \mathrm{IEP} / \Delta \mathrm{t})$ is evaluated (Figure $6 \mathrm{~b})$. This fact shows that both parameters are dependent on the structural changes to which the precursors are subjected during aging. This strong relationship between $\Delta \mathrm{IEP} / \Delta \mathrm{t}$ and $\Delta \mathrm{pH}_{\mathrm{rx}} / \Delta \mathrm{t}$ was confirmed through a correlation analysis $(r=0.9492$, $p=0.0002)$.

\subsection{Surface Evidence of the Formation of Imogolite}

The combined use of different analytical techniques (FTIR, XRD, TEM and EM) allowed the identification of two key stages that occur during aging in the synthesis of imogolite, which are described by the mechanisms of formation of imogolite proposed by Maillet et al. and Yucelen et al. $[18,19]$.

The first stage is the formation of precursors that will evolve into imogolite, and, according to Maillet et al., they correspond to short-range amorphous subnanometric species. However, according to Yucelen et al., the precursors formed are of the Keggin-ion type, and both precursors originate from the hydrolysis of the starting reagents [18,19].

The growth and development of these precursors into more complex structures (i.e., raft and ring structures) occurs through a self-assembly mechanism that originates during Ostwald ripening [42-44], a process associated with reactions that involve thermal aging, such as the case of imogolite synthesis $[11,14,16,19]$. These processes are those that produce the most significant changes in the precursors at the structural and surface level, as indicated by the IEP and $\mathrm{pH}_{\mathrm{rx}}$ values (Figure 5).

However, with respect to the growth of the imogolite tubes (i.e., the second stage), both mechanistic models differ on the route that converts the annular precursors into nanotubes. According to Maillet et al., the formation of imogolite occurs as a consequence of successive collisions of the nanotube fragments (i.e., tip-tip collisions) [18]. If the growth process of imogolite occurs along this route, the electrokinetic behavior of the precursors, which is reflected in the IEP values, should be similar starting from $48 \mathrm{~h}$ of aging until the end of the aging process. This similarity occurs because the precursors formed in this time have a surface with similar active sites of the imogolite nanotubes, which is not what was determined from the electrophoretic measurements (Table 2).

Our experimental evidence of the surface behavior of the different precursors obtained during the synthesis of imogolite suggests that its growth is governed by dissolution and condensation processes of those precursors that are in thermodynamically less stable states; the precursors rearrange themselves until the nanotubes are produced, as proposed by Yucelen et al. [19], which accounts for the variations in the IEP and $\mathrm{pH}_{\mathrm{rx}}$ values observed in this study (Figures 3 and 6; Table 2).

The surface differentiation observed in the precursors due to the effect of the substitution of the $-\mathrm{OH}$ groups that belong to $\equiv \mathrm{Al}-\mathrm{OH}$ by $\mathrm{O}_{3} \mathrm{SiOH}$ and the one-dimensional growth of the imogolite nanotubes are stages that are highly unfavored from the standpoint of entropy. However, the energy 
released during both processes, and mainly during the condensation of the precursors (i.e., the oxolation mechanism), contributes to the enthalpy factor, which explains the favorable formation of imogolite $[16,44,45]$, as strongly evidenced by the changes in the surface composition of the precursors.

Our results allow a better understanding of surface reactivity changes during the imogolite aging process. This information is relevant to the design of new nanomaterials based on imogolite. The elaboration of nanocables based on metals such as $\mathrm{Cu}, \mathrm{Ag}$, and $\mathrm{Au}$ insulated by an imogolite coating [19,28] could be considered in electrical nanodispositives [46]. A Cu@imogolite, Ag@imogolite or Au@imogolite nanocable is possible because the imogolite synthesis conditions (considering the acidic $\mathrm{pH}$ conditions during imogolite synthesis) promote the adsorption of cations onto $\equiv$ Si-OH surface active groups located in the inner surface of imogolite precursors [4].

\section{Conclusions}

Micrographs taken at different stages of preparation showed the structures formed during the aging process, which evolve from amorphous structures to imogolite nanotubes. The FTIR spectra confirmed the presence of protoimogolite during the first hours of synthesis and the formation of a ring-type structure at $72 \mathrm{~h}$ of aging, after which no important changes were observed by FTIR at longer aging times. These results indicate that this technique loses sensitivity after the ring-type precursor is formed.

However, the surface and structural changes, such as the formation, evolution, and growth of the precursors, can be followed until the final structure of imogolite is obtained through the variations in the IEP obtained by EM. This approach allows the interpretation of the surface phenomena that occur during the aging of imogolite (i.e., self-assembly and Ostwald ripening). We established that, during the process of imogolite formation, the precursors present in the solution evolve into different types of structures (i.e., raft, ring and nanotube structures) as a result of the substitutions of -OH of the $\equiv \mathrm{Al}-\mathrm{OH}$ groups by $\mathrm{O}_{3} \mathrm{SiOH}$. The increase in the IEP values is the consequence of structural and surface changes that occur in the aging process to obtain imogolite, which are due to the observed phenomenon of surface differentiation, where the outer and inner surfaces have different electrophoretic behaviors. The PZSE of imogolite indicated that $\equiv \mathrm{Al}-\mathrm{OH}$ and $\equiv \mathrm{Si}-\mathrm{OH}$ groups are located on clearly separate surfaces in view of the difference observed between the IEP and PZSE values. The condensation of the precursors caused a decrease in the $\mathrm{pH}_{\mathrm{rx}}$, which was significant between 48 and $72 \mathrm{~h}$ of aging - a time during which the predominant structure is the ring type.

Based on our results, the critical stage in the synthesis of imogolite corresponds to the formation of a ring type structure that, from a thermodynamic point of view, most likely led to a globular structure (i.e., an allophane-like structure); however, the high dilution, the $\mathrm{Al} / \mathrm{Si}$ ratio, and the extended aging period used during the synthesis hindered this transformation, which caused the terminal functional groups - the constituents of the tip of the annular structure (三Al-OH and $\equiv \mathrm{Si}-\mathrm{OH}$ ) - to constantly consume precursors in an attempt to achieve a globular structure. As a consequence, we observed only one-dimensional growth of the precursors, which evolved into imogolite. 


\section{Acknowledgments}

Financial support of this work by FONDECYT under Project 1070116 and by the Center for the Development of Nanoscience and Nanotechnology (CEDENNA) is gratefully acknowledged. We are especially grateful to Fernando Pinto, Miguel Juanco, and Martín Treps for technical assistance. Nicolás. Arancibia-Miranda acknowledges a scholarship from CONICYT (Chile).

\section{References}

1. Bursill, L.A.; Peng, J.L.; Bourgeois, L.N. Imogolite: An aluminosilicate nanotube material. Philog. Mag. A 2000, 80, 105-117.

2. Cradwick, P.D.G.; Farmer, V.C.; Russell, J.D.; Masson, C.R.; Wada, K.; Yoshinaga, N. Imogolite-A hydrated aluminium silicate of tubular structure. Nat. Phys. Sci. 1972, 240, 187-189.

3. Farmer, V.C.; Fraser, A.R.; Tait, J.M. Synthesis of imogolite: A tubular aluminium silicate polymer. J. Chem. Soc. Chem. Commun. 1977, 13, 462-463.

4. Denaix, L.; Lamy, I.; Bottero, J.Y. Structure and affinity towards $\mathrm{Cd}^{2+}, \mathrm{Cu}^{2+}, \mathrm{Pb}^{2+}$ of synthetic colloidal amorphous aluminosilicates and their precursors. Colloid Surf. 1999, 158, 315-325.

5. Farmer, V.C.; Adams, M.J.; Fraser, A.R.; Palmieri, F. Synthetic imogolite-Properties, synthesis, and possible applications. Clay Miner. 1983, 18, 459-472.

6. Geraldo, D.A.; Arancibia-Miranda, N.; Villagra, N.A.; Mora, G.C.; Arratia-Perez, R. Synthesis of CdTe QDs/single-walled aluminosilicate nanotubes hybrid compound and their antimicrobial activity on bacteria. J. Nanopart. Res. 2012, 14, 1286-1293.

7. Imamura, S.; Hayashi, Y.; Kajiwara, K.; Hoshino, H.; Kaito, C. Imogolite-A possible new type of shape-selective catalyst. Ind. Eng. Chem. Res. 1993, 32, 600-603.

8. Qi, X.; Yoon, H.; Lee, S.H.; Yoon, J.; Kim, S.J. Surface-modified imogolite by 3-APS-OsO 4 complex: Synthesis, characterization and its application in the dihydroxylation of olefins. $J$. Ind. Eng. Chem. 2008, 14, 136-141.

9. Suzuki, M.; Inukai, K.; Maeda, M. Synthesis of imogolite from inorganic solution influence of solution concentration on forming precursor for the synthesis of large quantities of imogolite. J. Vac. Soc. Jpn. 2005, 49, 29-33.

10. Levard, C.; Masion, A.; Rose, J.; Doelsch, E.; Borschneck, D.; Dominici, C.; Ziarelli, F.; Bottero, J.Y. Synthesis of imogolite fibers from decimolar concentration at low temperature and ambient pressure: A promising route for inexpensive nanotubes. J. Am. Chem. Soc. 2009, 131, 17080-17081.

11. Levard, C.; Rose, J.; Thill, A.; Masion, A.; Doelsch, E.; Maillet, P.; Spalla, O.; Olivi, L.; Cognigni, A.; Ziarelli, F.; et al. Formation and growth mechanisms of imogolite-like aluminogermanate nanotubes. Chem. Mater. 2010, 22, 2466-2473.

12. Yang, H.X.; Wang, C.; Su, Z.H. Growth mechanism of synthetic imogolite nanotubes. Chem. Mater. 2008, 20, 4484-4488.

13. Mukherjee, S.; Kim, K.; Nair, S. Short, highly ordered, single-walled mixed-oxide nanotubes assemble from amorphous nanoparticles. J. Am. Chem. Soc. 2007, 129, 6820-6826. 
14. Mukherjee, S.; Bartlow, V.A.; Nair, S. Phenomenology of the growth of single-walled aluminosilicate and aluminogermanate nanotubes of precise dimensions. Chem. Mater. 2005, 17, 4900-4909.

15. Barrett, S.M.; Budd, P.M.; Price, C. The synthesis and characterization of imogolite. Eur. Polym. J. 1991, 7, 609-612.

16. Jolivet, J.P.; Chanéac, C.; Chiche, D.; Cassaignon, S.; Durupthy, O.; Hernandez, J. Basic concepts of the crystallization from aqueous solutions: The example of aluminum oxy(hydroxi)des and aluminosilicates. C. R. Geosci. 2011, 343, 113-122.

17. Wada, S.-I. Imogolite synthesis at $25^{\circ} \mathrm{C}$. Clays Clay Miner. 1987, 5, 379-384.

18. Maillet, P.; Levard, C.; Spalla, O.; Masion, A.; Rose, J.; Thill, A. Growth kinetic of single and double-walled aluminogermanate imogolite-like nanotubes: An experimental and modeling approach. Phys. Chem. Chem. Phys. 2011, 13, 2682-2689.

19. Yucelen, G.I.; Choudhury, R.; Vyalikh, A.; Scheler, U.; Beckham, H.W.; Nair, S. Formation and growth mechanisms of imogolite-like aluminogermanate nanotubes. J. Am. Chem. Soc. 2011, 133, 5397-5412.

20. Thill, A.; Maillet, P.; Guiose, B.; Spalla, O.; Belloni, L.; Chaurand, P.; Auffan, M.; Olivi, L.; Rose, J. Physico-chemical control over the single- or double-wall structure of aluminogermanate imogolite-like nanotubes. J. Am. Chem. Soc. 2012, 134, 3780-3786.

21. Gil-Llambías, F.J.; Escudey-Castro, A.M. Use of zero point charge measurements in determining apparent surface coverage of molybdena in $\mathrm{MoO}_{3} / \mathrm{Al}_{2} \mathrm{O}_{3}$ catalysts. J. Chem. Soc. Chem. Commun. 1982, 9, 478-479.

22. Escudey, M.; Galindo, G.; Ervin, J. Effect of iron oxide dissolution treatment on the isoelectric point of allophanic soils. Clays Clay Miner. 1986, 34, 108-110.

23. Panagiotou, G.D.; Petsi, T.; Bourikas, K.; Kordulis, C.; Lycourghiotis, A. The interfacial chemistry of the impregnation step involved in the preparation of Tungsten(VI) supported titania catalysts. J. Catal. 2009, 262, 266-279.

24. Díaz de León, J.N.; Picquarta, M.; Villarroel, M.; Vrinat, M.; Gil Llambias, F.J.; Murrieta, F.; de los Reyes, J.A. Effect of gallium as an additive in hydrodesulfurization $\mathrm{WS}_{2} / \gamma-\mathrm{Al}_{2} \mathrm{O}_{3}$ catalysts. J. Mol. Catal. A 2010, 323, 1-6.

25. Taffarel, S.R.; Rubio, J. On the removal of $\mathrm{Mn}^{2+}$ ions by adsorption onto natural and activated Chilean zeolites. Miner. Eng. 2010, 23, 771-779.

26. Cáceres, L.; Escudey, M.; Fuentes, E.; Báez, M.E. Modeling the sorption kinetic of metsulfuron-methyl on Andisols and Ultisols volcanic ash-derived soils: Kinetics parameters and solute transport mechanisms. J. Hazard. Mater. 2010, 179, 795.

27. Sposito, G. The operational definition of the zero point of charge in soils. Soil Sci. Soc. Am. J. 1981, 45, 292-297.

28. Vayssieres, L. On the effect of nanoparticle size on water-oxide interfacial chemistry. J. Phys. Chem. 2009, 113, 4733-4736.

29. Qafoku, N. Terrestrial nanoparticles and their controls on soil-/geo-processes and reactions. Adv. Agron. 2010, 107, 33-91.

30. Hu, J.; Kannangara, G.S.K.; Wilson, M.A.; Reddy, N. The fused silicate route to protoimogolite and imogolite. J. Non-Cryst. Solids. 2004, 347, 224-230. 
31. Wilson, M.A.; Lee, G.S.H.; Taylor, R.C. Tetrahedral rehydration during imogolite formation. J. Non-Cryst. Solids. 2001, 296, 172-181.

32. McBride, M.B.; Farmer, V.C.; Russell, J.D.; Tait, J.M.; Goodman, B. Iron substitution in aluminosilicate sols synthesized at low pH. Clay Miner. 1984, 19, 1-8.

33. Gil, B.; Zones, S.I.; Hwang, S.-J.; Bejblová, M.; Čejka, J. Acidic properties of SSZ-33 and SSZ-35 novel zeolites: A complex infrared and MAS NMR study. J. Phys. Chem. C 2008, 112, 2997-3007.

34. Harsh, J.B.; Traina, S.J.; Boyle, J.; Yang, Y. Adsorption of cations on imogolite and their effect on surface charge characteristics. Clays Clay Miner. 1992, 40, 700-706.

35. Farmer, V.C.; Smith B.F.L.; Tait, J.M. Stability free-energy and heat of formation of imogolite. Clay Miner. 1979, 14, 103-107.

36. Bonelli, B.; Bottero, I.; Ballarini, N.; Passeri, S.; Cavani, F.; Garrone, G. IR spectroscopic and catalytic characterization of the acidity of imogolite-based systems. J. Catal. 2009, 264, 15-30.

37. Gustafsson, J.P. The surface chemistry of imogolite. Clays Clay Miner. 2001, 49, 73-80.

38. Arancibia-Miranda, N.; Escudey, M.; Molina, M.; García-González, M.T. Use of isoelectric point and $\mathrm{pH}$ to evaluate the synthesis of a nanotubular aluminosilicate. J. Non-Cryst. Solids. 2011, 357 , 1750-1756.

39. Yucelen, G.I.; Choudhury, R.P.; Leisen, J.; Nair, S.; Beckham, H.W. Defect structures in aluminosilicate single-walled nanotubes: A solid-state nuclear magnetic resonance investigation. J. Phys. Chem. C 2012, 116, 17149-17157.

40. Tsuchida, H.; Ooi, S.; Nakaishi, K.; Adachi, Y. Effects of $\mathrm{pH}$ and ionic strength on electrokinetic properties of imogolite. Colloid Surf. 2005, 265, 131-134.

41. Huittinen, N.; Rabung, T.; Lutzenkirchen, J.; Mitchell, S.C.; Bickmore, B.R.; Lehto, J.; Geckeis, H. Sorption of $\mathrm{Cm}(\mathrm{III})$ and $\mathrm{Gd}(\mathrm{III})$ onto gibbsite, $\alpha-\mathrm{Al}(\mathrm{OH})_{3}$ : A batch and TRLFS study. J. Colloid Interface Sci. 2009, 332, 158-164.

42. Singh, B.P.; Menchavez, R.; Takai, C.; Fuji, M.; Takahashi, M. Stability of dispersions of colloidal alumina particles in aqueous suspensions. J. Colloid Interface Sci. 2005, 291, 181-186.

43. Steefel, C.I.; van Cappellen, P.; Nagy, K.L.; Lasaga, A.C. Modeling water-rock interaction in the surficial environment: The role of precursors, nucleation and Ostwald ripening. Chem. Geol. 1990, 84, 322-325.

44. Brinker, C.J.; Scherer, G.W. Sol-Gel Science. In The Physics and Chemistry of Sol-Gel Processing; Harcourt Brace Jovanovich: Boston, MA, USA, 1989.

45. Yucelen, G.I.; Kang, D.-Y.; Guerrero-Ferreira, R.C.; Wright, E.R.; Beckham, H.W.; Nair, S. Shaping single-walled metal oxide nanotubes from precursors of controlled curvature. Nano Lett. 2012, 12, 827-832.

46. Kuc, A.; Heine, T. Shielding nanowires and nanotubes with imogolite: A route to nanocables. Adv. Mater. 2009, 21, 4353-4356.

(C) 2013 by the authors; licensee MDPI, Basel, Switzerland. This article is an open access article distributed under the terms and conditions of the Creative Commons Attribution license (http://creativecommons.org/licenses/by/3.0/). 